\title{
The Lagos coast - Investigation of the long-term morphological impact of the Eko Atlantic City project
}

\author{
K.M. van Bentum ${ }^{1,2,3}$, C.W. Hoyng ${ }^{2}$, M. Van Ledden ${ }^{1,2}$, A.P. Luijendijk ${ }^{1,3}$ and M.J.F. Stive ${ }^{1}$ \\ ${ }^{1}$ Hydraulic Engineering, Delft University of Technology, Stevinweg 1, 2628 CN , Delft, The Netherlands, kvbentum@gmail.com \\ ${ }^{2}$ Royal Haskoning, George Hintzenweg 85, 3068 AX Rotterdam \\ ${ }^{3}$ Deltares, Rotterdamseweg 185, 2629 HD Delft
}

\begin{abstract}
The Lagos coast has been suffering high rates of erosion since the construction of three harbour moles, i.e. the West Mole, East Mole and the Training Mole, at the tidal inlet connecting the Lagos Lagoon to the South Atlantic Ocean. To provide for a permanent erosion mitigation measure and to create residential and commercial area for circa 400,000 people, the Eko Atlantic City project has been initiated in 2008. In front of the eroded coast, approximately $9 \mathrm{~km}^{2}$ of land will be reclaimed and protected by a revetment.

In this study the long-term and large-scale morphological behavior of the Lagos coast is investigated and subsequently the long-term morphological impact of the project is assessed. First, a conceptual model is created, in which the historical development of the coast is discussed. The long-term morphological behavior of the coast downstream of the inlet is determined by two main factors: sediment accumulation at the West Mole and sediment import into the tidal inlet and the lagoon, induced by disturbance of the morphological equilibrium by sea level rise and dredging activities.

Using the numerical simulation model Unibest, the long-term impact of Eko Atlantic City is assessed. It is concluded that the construction of Eko Atlantic City will not change the total erosion volumes downstream of the inlet. However, as the revetment of the project retains the coast, the erosion will be shifted towards downstream. Downdrift of the project, the erosion rates are locally relatively high. The shape of the sea defence has been designed to minimize the local erosion effect. A monitoring and mitigation strategy has been recommended to monitor this effect and instruct coastal protection management actions to be implemented if required.
\end{abstract}

\section{INTRODUCTION}

Lagos is situated at the western part of the Nigerian coast around a tidal inlet which leads to the Lagos Lagoon. In 1908 man started to interfere with the natural coastal system by the construction of three harbour moles at the tidal inlet. These moles are the West Mole, the Training Mole and the East Mole. Nowadays, the tidal inlet is called the Commodore Channel and it constitutes the seaside entrance to the Lagos Harbor, see Figure 1.

As of the completion of the moles, the Lighthouse Beach, situated updrift of the inlet, expanded about 800 meters over circa hundred years due to sediment trapping at the West Mole. Consequently, the Bar Beach, located downdrift of the inlet, suffered enormous rates of erosion. Over roughly hundred years the total retreat of the coast has reached values of more than one kilometer.

To counteract the large loss of beach width due to the erosion, man started to apply nourishments on the Bar Beach around 1960. Enormous volumes of sediment have been supplied to the beach, but it kept on eroding anyhow. An additional problem at Lagos is the growing population, entailing large space demands for residential, commercial and recreational activities.

To cope with this space deficit and the land loss due to the erosion of the Bar Beach, the private project developer South Energyx Nigeria Ltd. (SENL) has initiated the Eko Atlantic City Development Project. This project comprises a land reclamation of $9 \mathrm{~km}^{2}$ in front of the Bar Beach, directly east of the East Mole, see Figure 2. The newly reclaimed land is protected against erosion by a revetment, which has a length of roughly $8.4 \mathrm{~km}$. Royal Haskoning provides, among others, the consulting services for the marine works of Eko Atlantic City.

This paper summarizes the results of a study into the long-term morphological impact of Eko Atlantic City on the adjacent coast of Lagos, Nigeria, performed by van Bentum [2012]. Three research questions (RQ) have been posed in this project:

RQ1: What are the governing processes and mechanisms determining the long-term and large-scale morphological behavior of the Lagos coast?

RQ2: What was the influence of the construction of the Lagos Harbour Moles and other human interferences on the historical coastline development?

RQ3: How does the construction of Eko Atlantic City change the present morphological processes?

A time span of 10 years after construction of Eko Atlantic City is defined herein as long-term. This work builds upon the analysis from Royal Haskoning [2011] in which the initial morphological effects of Eko Atlantic City were assessed.

\section{RESEARCH APPROACH}

The study has been divided into two parts. First, the governing processes and mechanisms determining the long-term and largescale morphological behavior of the Lagos coast have been identified. Information sources have been (scarce) reports, historical maps and nourishment data in the area of interest. Based on these sources, a conceptual model of the historical development 


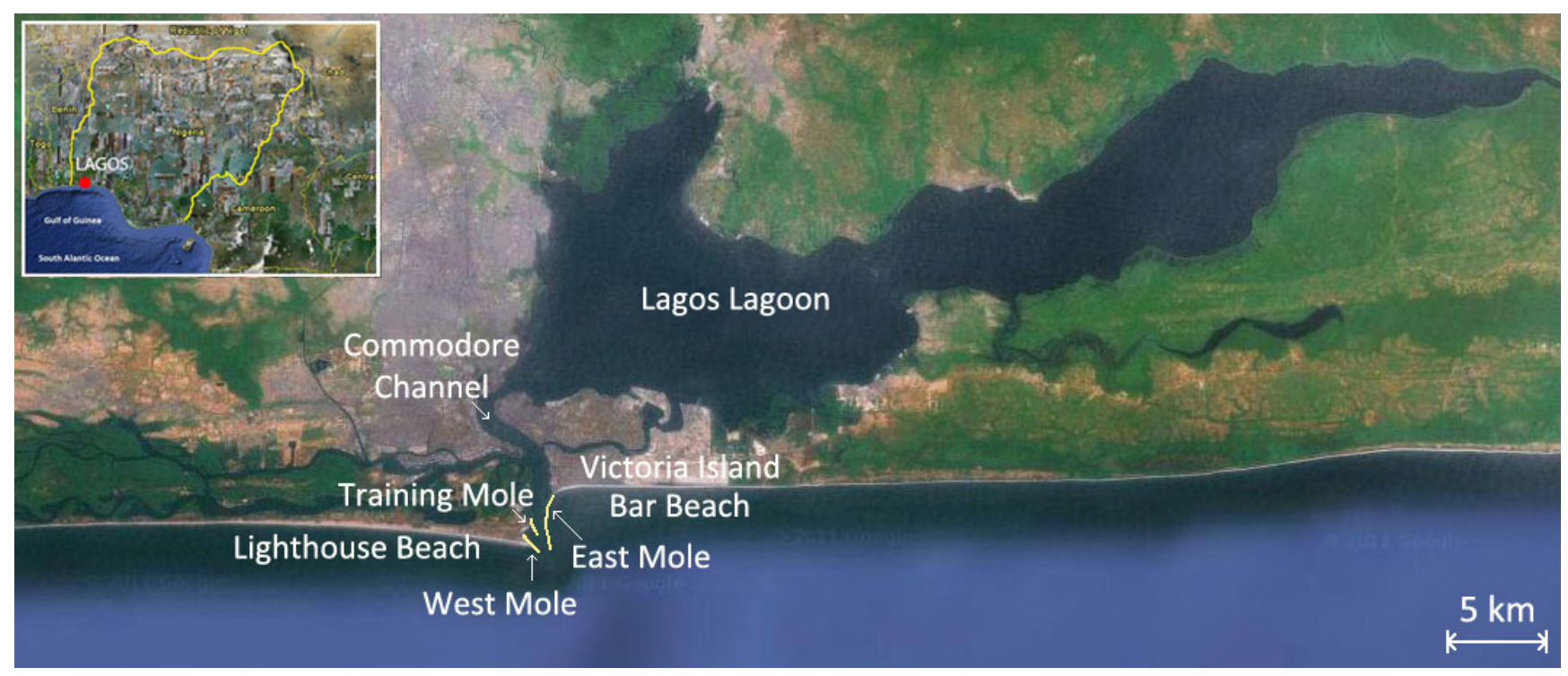

Figure 1: Overview of Lagos [after Google Earth, 2010]

of the Lagos coast has been created. In the conceptual model, the governing sediment fluxes, sources and sinks in the Lagos coastal system are quantified via consideration of the sediment balance at the coast of Lagos. This conceptual model is subsequently used to setup hypotheses regarding the future morphological development of the Lagos coast.

In the second part of the study these hypotheses have been investigated using the numerical simulation model Unibest. The model has been verified against the historical development of the Lagos coast first. Thereafter, the model has been applied to assess the impact of several human interferences such as the construction of Eko Atlantic City. Uncertainties have been dealt with using different scenarios for the magnitude of sea level rise and the sediment sink of the Lagos Lagoon and the Commodore Channel. These simulations provide useful insight into the extent and timescale of erosion along the coast. Recommendations are given on how to mitigate these effects.

\section{HISTORICAL ANALYSIS}

The area of interest in this study has been defined by the morphological influence zone of the Lagos Harbor Moles. Using the 'Single line theory' of Pelnard-Considere [1956] (see e.g. Bosboom and Stive [2010]), the influence of the Lagos Harbor Moles in 2020 (i.e. ten years after construction of Eko Atlantic City) reaches circa $25 \mathrm{~km}$ upstream and $25 \mathrm{~km}$ downstream.

As the governing processes and mechanisms are not constant over time, the historical development of the Lagos coast has been considered in four periods. The division in time has been made using the historical human interventions at the Lagos coast.

The first significant human intervention at the Lagos coast is the construction of the three harbor moles, between 1908 and 1912 . Thereafter, man started to apply nourishments around 1958, which is also the time that man started to dredge the Commodore

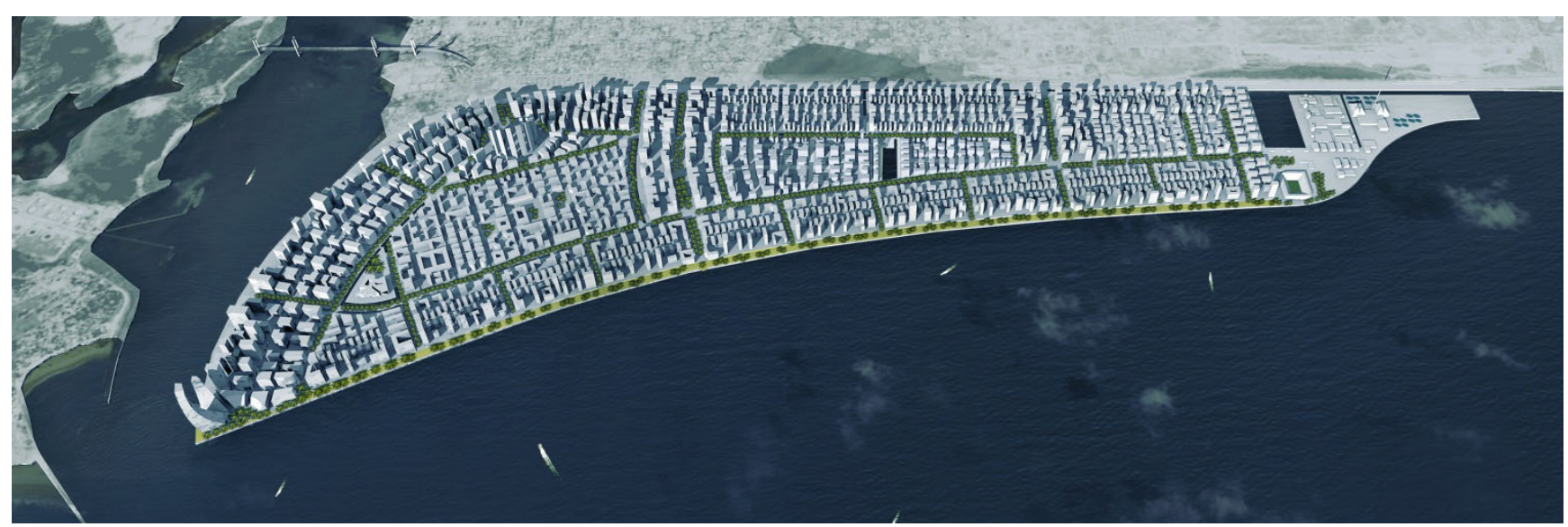

Figure 2. Artist's impression of the Eko Atlantic City [made by Royal Haskoning] 
Channel, for navigational purposes, and the Lagos Lagoon, to obtain sediment for construction activities. The most recent human act at the Lagos coast is the commencement of the construction of Eko Atlantic City in 2008. Using these data, the historical development is divided in the periods: 'Before 1910', 1910 1960, 1960 - 2010 and 'After 2010' [van Bentum, 2012].

\section{Governing processes and mechanisms}

The wave climate at Lagos consists of persistent, high-energy swell waves, which reach the coast of Lagos with a mean direction of $188^{\circ}$. Hereby, a mean eastward longshore sediment transport of roughly $600,000 \mathrm{~m}^{3} /$ year to $700,000 \mathrm{~m}^{3} /$ year is induced. It has been assumed that this longshore sediment transport rate was approximately constant over the years.

In general, the whole Lagos coast suffers erosion due to the high rates of relative sea level rise, induced by the Eustatic sea level rise combined with soil subsidence. The rates of subsidence are high, due to natural dewatering and compaction of the soil but also due to human-induced water extraction in het coastal zone.

According to the 'Bruun rule'[Bruun, 1962], a cross-shore profile responds in the long-term to an increased mean sea level such that a new equilibrium upper shoreface profile develops relative to the new mean sea level. The coast recedes as result of the (relative) sea level rise, because the sea level rise causes more sediment accommodation space. This induces erosion of the beach, due to the landward shift of the profile. The rate of relative sea level rise is assumed to be constant over time, so this value does not differ between the different periods.

The high rates of erosion downdrift of the inlet, i.e. at the Bar Beach, are not induced by sea level rise alone however. The governing factors inducing the erosion of Bar Beach are the accumulation of sediment by the West Mole and the import of sediment into the Commodore Channel and the Lagos Lagoon. The sediment import into the Commodore Channel and the lagoon occurs due to sea level rise, dredging of the channel and dredging of the lagoon. These processes disturb the morphodynamic equilibrium of the inlet and the lagoon, as they create additional sediment accumulation space by enlarging the depth of the channel respectively the lagoon. This leads to a so-called sediment demand in the lagoon and the tidal inlet.

The result of the sediment trapping at the West Mole and the sediment import into the tidal inlet and the lagoon is that almost no sediment is able to bypass the East Mole. Thereby, a sediment deficit in the longshore current downdrift of the tidal inlet arises. The exact volume of the bypass, however, differs per period. Subsequently, the Bar Beach starts to erode, to provide for a sediment source to the longshore sediment transport. The volume of erosion is thus dependent on the sediment volume able to bypass the East Mole.

\section{Impact human interventions}

The impact of the Lagos Harbor Moles on the historical development of the Lagos coast is visible in the differences in beach widths updrift and downdrift of the tidal inlet. The
Lighthouse Beach, located updrift of the inlet, expanded about 800 meters over 100 years, due to the sediment accumulation at the West Mole. On the contrary, the Bar Beach, situated downdrift of the inlet, eroded even more than one kilometer since the construction of the moles.

As of 1960, man started to apply mitigation measures at the Bar Beach to counteract the erosion. Because the retreat of the coast had become very severe, mitigation measures were required directly. Although erosion of the Bar Beach was not prevented by the artificial sediment supply with a mean volume of 580,000 $\mathrm{m}^{3} /$ year, the nourishments clearly have had an alleviating effect on the erosion. If the nourishments had not been conducted, the erosion of the Bar Beach would have been much worse.

Another human intervention in the Lagos coastal system is the dredging of the Commodore Channel and the dredging of the Lagos Lagoon. The removal of sediment disturbs the morphodynamic equilibrium of the tidal inlet and the lagoon, and additional sediment accumulation space is created. Therefore, the tidal inlet and the lagoon import sediment to restore their dynamic equilibrium. Hereby, the sediment volume bypassing the East Mole is decreased and the Bar Beach suffers even more erosion.

\section{Conceptual sediment balances}

Based on the governing processes and mechanisms described above, a sediment balance of the Lagos coast has been set up for each period. In doing this, the sediment fluxes, sources and sinks are expressed as a percentage of the total volume of longshore sediment transport. The assumption underlying the setup of the sediment balances is that far upstream and far downstream of the inlet, beyond the influence of the moles, the volume of longshore sediment transport is hundred per cent, schematised by ' $S$ '. In Figure 3, Figure 4 and Figure 5 the conceptual sediment balances are depicted per period (depicted in [van Bentum, 2012]).

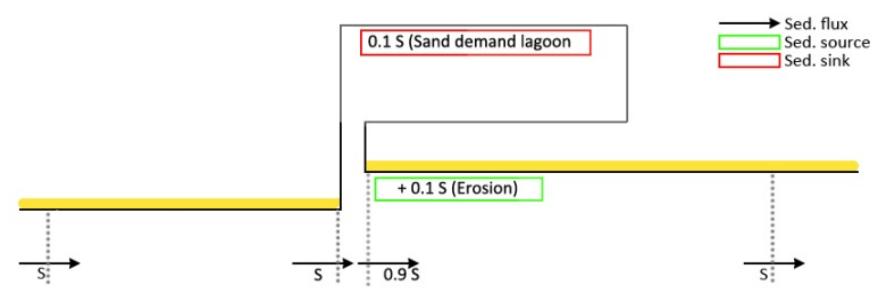

Figure 3. Conceptual sediment balance 'Before 1910'

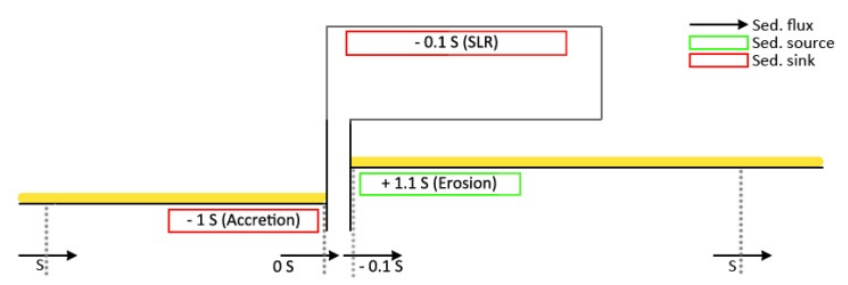

Figure 4. Conceptual sediment balance 1910 - 1960 


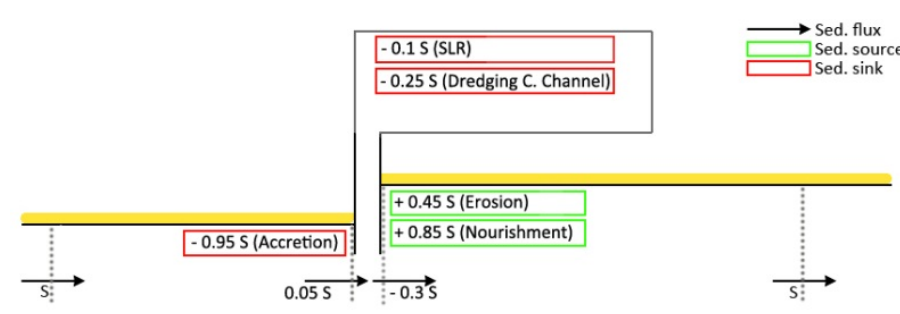

Figure 5. Conceptual sediment balance $1960-2010$

Using the results of the conceptual model, hypotheses on the long-term morphological development of the Lagos coast with the presence of Eko Atlantic City have been put forward. As discussed earlier, there are two main factors determining the morphological behavior of the Bar Beach: 1) the sediment trapping at the West Mole, and 2) the sediment import into the lagoon and into the Commodore Channel. Due to the sediment sink these processes constitute, the sediment volume bypassing the East Mole is limited.

\section{FUTURE COASTAL DEVELOPMENT}

To predict long-term morphological changes, the numerical simulation model Unibest ${ }^{1}$ has been applied. In short, the Unibest model can be used to compute longshore and cross-shore processes and the associated morphodynamics of beach profiles and coastline development. The model is especially suited for wave-dominated coasts.

The Unibest model consists of two modules, which run separately from each other: the LT (Longshore Transport) module and the CL (CoastLine) module. First the LT module is run and thereafter the output of the LT module run is used as input in the CL module. The advantage of the use of a 1D model such as the Unibest software is that a large coastal system can be analysed over large time spans. Since data of the Lagos coast is limited, the application of a 1D model is a justified choice in this study.

Using the Unibest model, the hypothetical future scenarios have been simulated. For the area of interest in this study, 11 profiles were defined along the coast, of which four were located in the shadow zone of the East Mole, to take into account the effect of diffraction. Each profile is characterized by a specific initial bathymetry and coastline orientation. In between the defined profiles, the coastal bathymetry has been obtained by linear interpolation between the two profiles. All profiles are defined perpendicular to the coast.

In short, the volumes of longshore sediment transport are computed in the LT module for every cross-section. These volumes provide a certain gradient in the longshore sediment transport between the profiles along the coast. These gradients are used in the CL module to define the accretion or erosion of the coast. Herein it is assumed that the layout of the cross-shore

\footnotetext{
${ }^{1}$ Unibest is an acronym for UNIform BEach Sediment Transport. The software is developed by Deltares; www.deltaressystems.com. The most recent version is of July 2011.
}

profiles does not change and that behind the (user defined) active depth no sediment transport occurs.

An example of the output of the Unibest model is shown in Figure 6, in which the simulated coastline in 2020 is depicted for both the scenario with the presence of Eko Atlantic City (in red) and without the presence of the project (in yellow). At the location of Eko Atlantic City, a revetment is put at the coastline by which erosion of the coast is prevented.

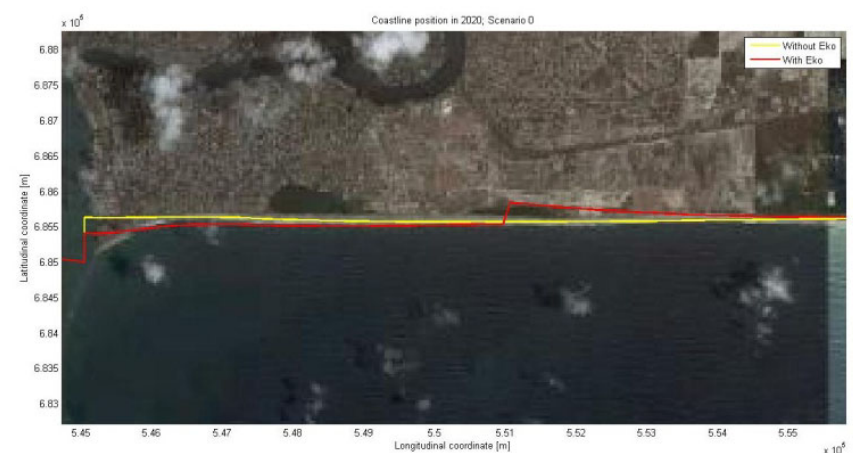

Figure 6. Simulated coastline in 2020. Red is with presence of Eko Atlantic City and yellow without the presence of the project

As stated above, due to the sediment sinks induced by sediment trapping at the West Mole and sediment import into the lagoon and the tidal inlet, the bypass along the East Mole is limited. Therefore, the coast downstream of the tidal inlet, the Bar Beach, erodes. The total volume of erosion occurring downstream of the tidal inlet is not altered by the presence of the Eko Atlantic City project.

The revetment of Eko Atlantic City fixes the coast of the newly reclaimed land, so further erosion of the Bar Beach is prevented. But, the erosion of the Bar Beach is shifted eastward by the construction of the project. As concluded in the conceptual model, the volume of erosion and the corresponding rate of beach retrogression are determined by the volume of sediment bypassing along the East Mole.

The erosion that would occur at the Bar Beach, without the construction of Eko Atlantic City, is spread quite equally over the beach. The erosion that occurs downstream the Eko Atlantic City project, on the contrary, reaches much higher values locally. So, although the total erosion volumes are equal, the erosion rates directly downstream of the project are increased significantly. Because the erosion volume downstream of the project is spread out over a larger distance than the distance over which the erosion is spread out if the project is not constructed, the erosion rates downstream Eko Atlantic City diminish rapidly. Moreover, the transition of the land reclamation towards the original shoreline has been altered into a less abrupt transition to reduce the local higher erosion values.

If the development of the erosion downstream of Eko Atlantic City is considered until 2060, it can be concluded that the erosion rates downstream of the project are highest just after the construction. Over the years, the erosion rates and the erosion 
volumes decrease somewhat, but the length of the erosion wave increases.

Therefore, keeping the longer-term effects of Eko Atlantic City in mind, and investigating the hinterland of the coast downdrift of Eko Atlantic City, it becomes clear that mitigation measures may be required. It is envisioned that a volume in the order of the longshore sediment transport must be nourished to prevent erosion of the coast downstream of the Eko Atlantic City project.

It is recommended to apply a monitoring campaign at the coast downstream of the Eko Atlantic City project. This is in line with the outcome of the Environmental Impact Assessment study for this project [Royal Haskoning, 2011]. Besides the additional advantage of acquiring more data of the Lagos coast, one can also react quickly to undesired scenarios. The analysis of the effects of the construction of Eko Atlantic City reveals the expected shift in erosion by the project, which can be counteracted by nourishments to ensure a stable beach downstream of the Eko Atlantic City project.

\section{CONCLUSIONS}

The analysis of the Lagos coast is summarized via answering the research questions.

RQ1: There are five governing processes and mechanisms determining the long-term and large-scale morphological behavior of the Lagos coast:

1) The persistent and high-energy swell waves, inducing a mean eastward longshore sediment transport. 2) The sediment trapping at the West Mole, limiting the sediment bypass along the mole. 3) The high relative sea level rise, creating additional sediment accumulation space. 4) Dredging of the Commodore Channel and the Lagos Lagoon, disturbing the morphodynamic equilibrium and creating extra sediment import. Concluding: the sediment volume bypassing along the East Mole is principally determined by the size of the sink formed by the sediment trapping at the West Mole and the sediment import into the Lagos Lagoon and the Commodore Channel.

RQ2: The influence of the construction of the Lagos Harbour Moles between 1908 and 1912 is visible in: significant accretion of the Lighthouse Beach of more than $800 \mathrm{~m}$, and severe erosion of the Bar Beach of more than one kilometer. Another human interference on the historical coastline development is the performance of nourishments, which had an alleviating effect on the erosion of Bar Beach. On the contrary, the dredging of the Commodore Channel and the Lagos Lagoon has worsened the erosion downstream of the tidal inlet.

RQ3: The construction of Eko Atlantic City does not alter the total volume of erosion occurring downstream of the tidal inlet. However, a shift in the location of erosion is caused by the presence of the revetment of the project. At the location of the project further erosion is prevented but downstream of the project, the erosion will increase locally.

A monitoring and mitigation strategy is recommended to monitor the effects of Eko Atlantic City and instruct coastal erosion protection management actions to be implemented if required.

\section{ACKNOWLEDGEMENT}

Royal Haskoning is acknowledged for initiating the study and for providing financial support and all data used in this study. Deltares is also thanked for the financial support and for the support on the Unibest software.

\section{REFERENCES}

Bosboom, J. and M.J.F. Stive (2010). Coastal Dynamics I, Delft. VSSD.

Bruun, P. (1962). Sea-Level Rise as a Cause of Shore Erosion. Journal of Waterways and Harbor Division. American Society of Civil Engineers.

Royal Haskoning: Westra, M., O. Scholl, W. de Jong, M. Reneerkens, J. Lansen, M. Lips and C. Hoyng (2011). Eko Atlantic City - Coastal Analysis Report. Nijmegen, Netherlands.

van Bentum, K.M. (2012). The Lagos coast - investigation of the long-term morphological impact of the Eko Atlantic City project. MSc, Delft University of Technology. 